\title{
materiales aislantes a base de vidrio espumado. ensayos para obtener la máxima espumación
}

La aplicación del cristal en forma de lana de vidrio para el aislamiento de los edificios es ya de uso muy corriente en España. E! Vitrofib, Fibravid, Glasfaser, Fiberglas $y$ otros productos de distintas marcas se emplean en el revestimiento de paredes, suelos, techos, tuberías, así como en conducciones de acondicionamiento de aire.

Las características, procedimientos de aplicación y las ventajas e inconvenientes de los aislamientos a base de estos materiales son ya conocidos por una gran mayoria de personas relacionadas con la construcción y, por esta razón, no se indican aquí sus particularidades; se mencionan estos materiales únicamente para resaltar el hecho de que el vidrio constituye un material de construcción interesantisimo, bien sea en forma de cristal plano, bloques, lana o vidrio espumado. Esta última modalidad es de la que se va a tratar en este artículo.

Un fin perseguido por los fabricantes de cristal durante muchos siglos ha sido obtener este producto totalmente transparente $y$ uniforme, procurando, por todos los medios, eliminar las burbujas gaseosas que en él se producian. Hoy día puede decirse que no sólo se ha logrado todo esto, sino que además se obtienen cristales con excepcionales caracteristicas de transparencia, dureza, resistencia, etc.

Sin embargo, aquellas molestas burbujas, que en otro caso constituian un grave inconveniente, no solamente se dejan en su masa, sino que intencionadamente se incrementan en una cantidad prevista y a un tamaño determinado, para con ello obtener un nuevo material de construcción de includable valor, ligero $y$ de excelentes cualidades aislantes. Este nuevo producto es el vidrio espumado. Debido a su rígida estructura no se desmorona y puede cortarse fácilmente en la forma que se desee, asi como taladrarlo con las herramientas ordinarias.

El vidrio espumado, es totalmente diferente por su aspecto al cristal; no transmite ni absorbe la humedad, $y$ no le afectan ni los vapores ni las emanaciones.

Estas propiedades se deben a su especial estructura, constituida por millones de dimi1)utas burbujas totaimente cerradas y aisladas entre si.

La formación de céiulas en el cristal es un proceso que se consigue al mezclar vidrio en polvo con un agente gasificador o espumante y someterlo a la acción del calor durante un tiempo muy reducido. En este periodo de calentamiento, el vidrio funde $y$ rodea a las partículas del agente espumante. Estas partículas comienzan a descomponer. se, u oxidarse, como sucede en este caso por la acción del calor, y el gas resultante queda aprisionado por la masa vitrea. Las células que se forman son muy numerosas y de pequeñisimas dimensiones.

Un buen número de productos pueden utilizarse como agentes para provocar la formación de las células. El carbono en sus di- 
versas formas, la dolomía y el carbonato cálcico han sido ensayados con éxito para lograr esta estructura espumosa en el vidrio. La cantidad óptima de agente espumante a introducir en una mezcla vitrea depende de la naturaleza física y química de éste. En un artículo aparecido en "Ceramic Industry" (ju lio, 1951), se da cuenta de unos ensayos para determinar las temperaturas y elementos indispensables para obtener la espumación optima.

Según dicho articulo, los factores que es preciso tener en cuenta para lograr una correcta fabricación de este materiai son muchos. De ellos se han elegido los tres más importantes, ya que tienen una influencia más. decisiva. Estos son los siguientes :

1. La composición del vidrio.

2. La temperatura de cocción.

3. El tamaño de las partículas de la mezcla.

Estos factores y sus efectos se estudian en forma puramente cualitativa. Para cada uno de ellos se han realizado diferentes experiencias.

\section{EFECTOS QUE SE OBTIENEN NI. VARIAR LA COMPOSICIÓN DEL VIDRIO}

Tra figura 1 muestra los efectos producidos al variar la composición del vidrio. Las probetas ensayadas fueron de $\mathbf{1 0}$ gramos:

$A$ es una mezcla vitrea para la fabricación de lana.

$B$ y $C$ son dos tipos de vidrio para botellas.

$D$ es un vidrio de ventana.

$E$ es un fundente vítreo de bajo punto de fusión.

La probeta $A$ se mantivo completamente viscosa a $1.600^{\circ} \mathrm{F}\left(871^{\circ} \mathrm{C}\right)$. La formación de células fué muy reducida, debido a que la presión de los gases fué insuficiente para vencer la resistencia que oponía la masa viscosa.

El vidrio de la probeta $E$ se hizo relativamente fluído a $871^{\circ} \mathrm{C}$ y las células se agruparon destruyendo la estructura uniforme del producto; la cual es indispensable para obtener sus características óptimas.

Las muestras $B, C$ y $D$ tuvieron un comportamiento intermedio, gozando de la vis-

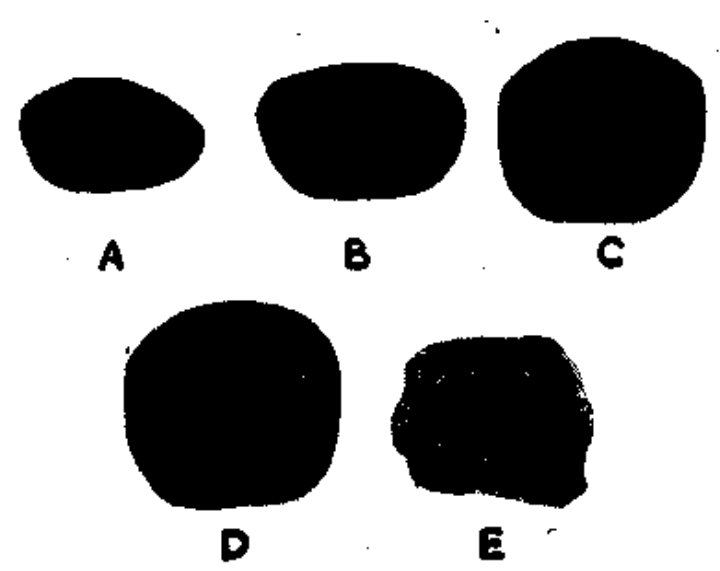

Fig. 1.-Efecto de la composición del vidrio, cccido a $1.600^{\circ} \mathrm{F}\left(871^{\circ} \mathrm{C}\right)$.

cosidad necesaria a la temperatura señalada. Vidrios con tales composiciones fueron los utilizados en las posteriores experiencias. Se descartaron los tipos $A$ y $E$ : el primero por su baja viscosidad y el segundo por tenerla excesiva.

La composición del cristal es también muy importante, ya que interviene en la durabilidad ante los agentes químicos. Posteriormente se ha intentado variar la composición del vidrio que se utiliza, con objeto de encontrar una mezcla que se dilate a una temperatura relativamente baja sin que disminuya su durabilidad.

\section{EFECTOS QUE SE ORTIENEN AL VARTAR LA TEMPERATURA DE COCCIÓN}

En la figura 2 pueden verse los efectos que se obtienen cuando se varía la 
temperatura sobre un material cuya composición es igual a la de un vidrio de ventana.

La primera muestra es una probeta de 10 gramos que no ha sufrido apenas altcración de volumen. Se ha iniciado la fusión del vidrio, pero no se observan indicios de formación de células.

En las probetas siguientes se inicia la aparición de células, lo cual se manifiesta por

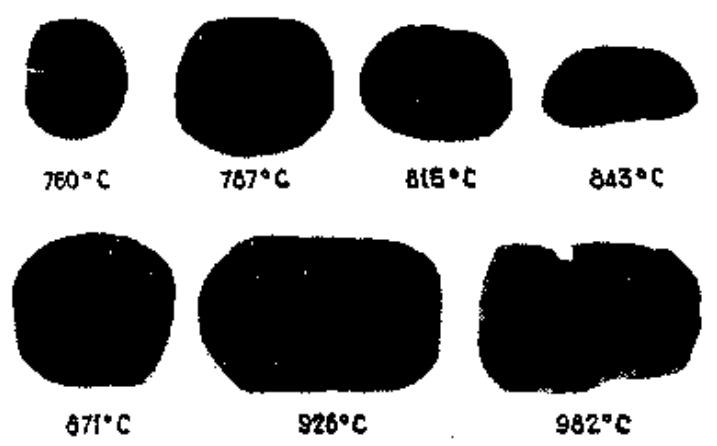

Pig. 2. -Efecto de ta temperatura de cocción.

el aumento de volumer. De 1500 a $1800^{\circ} \mathrm{F}$ $\left(815,5\right.$ a $\left.871^{\circ} \mathrm{C}\right)$, las células empiezan a ser uniformes y alcanzan el tamaño óptimo.

Cuando la cocción sobrepasa los $1600^{\circ} \mathrm{F}$ $\left(871^{\circ} \mathrm{C}\right)$, la probeta se hace excesivamente espumosa, decreciendo sensiblemente sus resistencias.

Para comprobar los efectos de las altas temperaturas se calentó una muestra a $1800^{\circ} \mathrm{F}\left(982^{\circ} \mathrm{C}\right)$, observándose la completa destrucción de su estructura celular y una pérdida total de resistencias.

\section{EFECTO DEL TAMANO DE LAS PARTÍCUIAS}

En la figura 3 pueden verse los efectos del tamaño de las partículas sobre la mezcla. Lo que se ve en dichas figuras son las secciones transversales o cortes de las muestras.

Se ha podido comprobar que hay un limite práctico para la cantidad de tiempo de molienda del desperdicio de vidrio. En las condiciones en que se realizó este ensayo se pudo apreciar que con cinco horas de molienda se obtenían unas muestras que presentaron un peșo específico muy bajo, conservando, sin embargo, una estructura celulat uniforme. El tamaño medio de las partículas fué del orden de $\mathbf{5}$ micras.

Una molienda que dura más de cinco horas produce una reducción en el tamaño de las burbujas y una disminución en el volumen total del producto.

Las probetas de arriba se cortesponden con las de abajo, excepto que, en el segundo caso, la formación celvlar se ha producido más de prisa debido a los treinta minutos de recalentamiento adicional a $1250^{\circ} \mathrm{F}$ $\left(676^{\circ} \mathrm{C}\right)$.

De todo ello se deduce lo siguiente:

1. El vidrio espumado puede hacerse con muy diversas composiciones, si reúne las

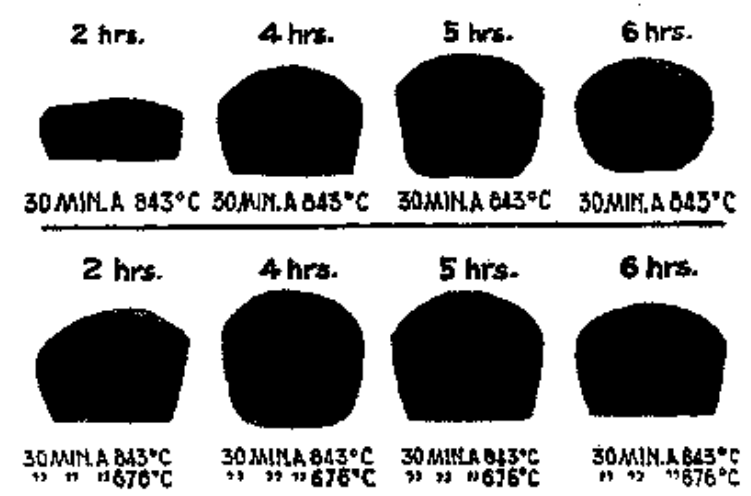

Fig. 3. - Efecto del tamaño de las partícutas.

adecuadas condiciones de molienda y cocción.

2. Cada composición vitrea tiene una reducida zona de temperaturas en la que se esponja bien.

3. Existe un tamaño óptimo de partículas y una distribución de éstas tal, que si se sobrepasa, mediante una molienda más prolongada, no se obtiene ninguna mejora aparente en la estructura celtular. 
Es preciso hacer constár que, aun cuando sólo se han investigado y considerado aquí tres factores, sin embargo, se ha conseguido un material que puede satisfacer plenamente las exigencias de los constructores. Es de esperar que el vidrio espumado será un material aislante, de uso corriente no sólo en edifícios públicos e industriales, sìno también en las casas particulares, ya que sus características de aislamiento, incombustibilidad, ligereza, durabilidad, etc., son excepcionales.

C. S. C. 